Abstracta Iranica Iranica

Revue bibliographique pour le domaine irano-aryen

Volume 27 | 2006

Comptes rendus des publications de 2004

\title{
Geschichte und Erinnerung im Islam. Göttingen, Vandenhoeck \& Ruprecht, 2004.
}

\section{Antoine Borrut}

\section{(2) OpenEdition}

1 Journals

\section{Édition électronique}

URL : http://journals.openedition.org/abstractairanica/6183

DOI : 10.4000/abstractairanica.6183

ISSN : 1961-960X

Éditeur :

CNRS (UMR 7528 Mondes iraniens et indiens), Éditions de l'IFRI

Édition imprimée

Date de publication : 15 mai 2006

ISSN : 0240-8910

Référence électronique

Antoine Borrut, "Geschichte und Erinnerung im Islam. Göttingen, Vandenhoeck \& Ruprecht, 2004. », Abstracta Iranica [En ligne], Volume 27 | 2006, document 260, mis en ligne le 02 janvier 2007, consulté le 25 septembre 2020. URL : http://journals.openedition.org/abstractairanica/6183 ; DOI : https:// doi.org/10.4000/abstractairanica.6183

Ce document a été généré automatiquement le 25 septembre 2020.

Tous droits réservés 


\title{
Geschichte und Erinnerung im Islam. Göttingen, Vandenhoeck \& Ruprecht, 2004.
}

\author{
Antoine Borrut
}

1 Cet ouvrage collectif s'inscrit dans le cadre des travaux conduits à l'université de Gießen sur les cultures du souvenir. La démarche se veut résolument pluridisciplinaire, ainsi qu'en témoigne la variété de la quinzaine de contributions, faisant suite à une introduction théorique très dense.

2 L'éditrice part du constat d'un déficit d'études sur la thématique de la mémoire en islam, en stigmatisant l'absence d'un Pierre Nora du Proche ou Moyen-Orient. Dans le même temps, force est de constater la place qu'occupe ce passé remémoré dans les discours contemporains, où l'on met volontiers en avant un «âge d'or » de l'islam premier (et/ou classique), et où l'on note l'omniprésence de la notion de turāt (patrimoine / héritage culturel).

3 Parmi les contributions, signalons notamment l'étude de G. Hendrich, sur la réception d'Averroès aujourd'hui, alors que $M$. Turki souligne l'importance de la thématique de la mémoire dans le monde arabe $\mathrm{du} 20^{\mathrm{e}} \mathrm{s}$., et les stratégies de l'oubli qui vont de pair. R. Hattemer s'interroge pour sa part sur la place des premiers califes dans la mémoire islamique contemporaine, et les motivations qui la sous-tendent, tandis que S. DamirGeilsdorf propose une enquête de même nature sur le concept «d'âge d'or » dans les discours d'aujourd'hui. J. Gertel aborde la question du souvenir et de la construction de soi, en tant que production d'un savoir social, et A. Hartmann met en lumière l'élaboration d'un discours anhistorique en s'interrogeant sur les rapports entre califat et pouvoir en islam.

4 On déplorera que cet ouvrage important ne soit pas pourvu d'une bibliographie générale qui en aurait fait un outil plus commode. À la longue liste de références théoriques sur la thématique de la mémoire proposée dans l'introduction et au fil de l'ouvrage (qui doit beaucoup aux travaux des chercheurs allemands, à l'instar de ceux, fondamentaux, de l'égyptologue J. Assmann), on ajoutera les travaux des médiévistes 
allemands, en particulier ceux d'O.-G. Oexle, G. Tellenbach, G. Althoff, J. Fried, etc. Un solide bilan de cette production est désormais disponible en français, voir M. Borgolte, "Memoria. Bilan intermédiaire d'un projet de recherche sur le Moyen Age », in : J.-C. Schmitt, O. G. Oexle (dirs.), Les tendances actuelles de l'histoire du Moyen Âge en France et en Allemagne. Actes des colloques de Sèvres (1997) et Göttingen (1998) organisés par le C.N.R.S. et le Max-Planck-Institut für Geschichte, Publications de la Sorbonne, Paris, 2003, p. 53-69 (à compléter par les contributions de J. Fried et de M. Lauwers dans le même volume).

INDEX

Thèmes : 7. Islam

\section{AUTEURS}

ANTOINE BORRUT

IFPO - Damas 